International Journal of Dentistry and Oral Science (IJDOS)

ISSN: $2377-8075$

\title{
Correlation between Gingival Expression of STAT1 and Chronic Periodontitis
}

Saeed $\mathrm{M}^{1,2}$, Sattari $\mathrm{M}^{1,2^{*}}$, Yeganeh $\mathrm{F}^{2}$, Sarira Shahnavaz ${ }^{2}$

${ }^{1}$ Iran Center for Dental Research, Dental School, Shahid Beheshti University of Medical Sciences, Iran.

${ }^{2}$ Department of Immunology, School of Medicine, Shahid Beheshti University of Medical Sciences, Tehran, Iran.

\section{Abstract}

Background: Periodontal disease is a most common inflammatory disease of periodontium. A wide variety of cytokines, chemokines and receptors are synthesized by gingival fibroblasts and inflammatory cells. Signal Transducer and Activator of Transcription-1 (STAT)-1 is a transcription factor that plays a key role in the process of intracellular signal transduction through the JAK-STAT pathway in response to inflammatory cytokines, Therefore plays an important role in inflammatory diseases.

So the aim of this study was to determine the correlation between STAT1 gingival gene expression and chronic periodontitis.

\begin{abstract}
Materials and Methods: For this purpose, gingival tissue sample were collected from 20 individuals with clinically healthy gingiva and 25 patients with moderate to severe chronic periodontitis. After homogenizing the gingival tissues, RNA was extracted by RNA isolation kit. After synthesis of cDNA, expression of STAT1 was evaluated by Real-time PCR.

Results: Higher expression of STAT1 was found in chronic periodontitis in comparison to clinically healthy gingiva $(\mathrm{P}<0.001)$.

Conclusion: In this study, STAT1 mRNA was significantly up-regulated in chronic periodontitis tissues as compared to healthy control tissues. These results suggest that the modulation of STAT1 expression may play an important role in the pathogenesis of the periodontal inflammatory process.
\end{abstract}

Keywords: Chronic Periodontitis; STAT1; Inflammation; Signal Transduction.

\section{*Corresponding Author:}

Mandana Sattari DDS, PhD,

Professor, Department of Immunology, Medical School, Shahed Beheshti University of Medical Sciences and Health Services, Evin, Shaheed Chamran Highway, Tehran, Iran.

Tel: +982123872545

Fax: +982122439970

E-mail: mandana.sattari@gmail.com

Received: September 21, 2015

Accepted: October 09, 2015

Published: October 13, 2015

Citation: Saeed M, Sattari M, Yeganeh F, Sarira Shahnavaz (2015) Correlation between Gingival Expression of STAT1 and Chronic Periodontitis. Int J Dentistry Oral Sci. 2(10), 158-162. doi: http://dx.doi. org $/ 10.19070 / 2377-8075-1500033$

Copyright: Sattari $\mathbf{M}^{\odot}$ 2015. This is an open-access article distributed under the terms of the Creative Commons Attribution License, which permits unrestricted use, distribution and reproduction in any medium, provided the original author and source are credited.

\section{Introduction}

Periodontal disease is the most common inflammatory disease of periodontium with the microbial and immunological etiologies [1-

3]. The disease is characterized by the inflammatory responses to the oral bacteria originating from the dental biofilm led to dental the alveolar bone destruction and eventually tooth loss [4]. Several risk factors are associated with the disease including smoking, host immune response, environmental, microbial factors and genetics [5-7].

It is defined as a biofilm-associated inflammatory disease of the tooth-supporting (periodontal) tissues, affecting about 10 percent of the world's population $[3,8]$. Chronic Periodontitis (CP) is one of the major types of periodontal diseases [9]. Although periodontopatic bacteria are considered as the primary etiologic factor in periodontal disease which trigger inflammatory responses by several virulence factor such as lipopolysaccharide (LPS), tissuedegrading enzymes, lipothetic acid (LTA) and peptidoglycans, but much of the damage that occurred during periodontal destruction is attributed to the host inflammatory responses elicited by these microorganisms [9-12].

It has been observed that inflammatory cytokines such as IL-1, IL-6, TNF- $\alpha$, IL-12, IL-21 and interferon gamma, regulate inflammation in periodontal disease [7, 12-14]. The performance of these molecules requires the intracellular transcription factors [15]. Signal Transducer and Activator of Transcription-1 (STAT)1 is a transcription factor that plays a key role in the process of intracellular signal transduction through the Janus kinase/signal transducers and activators of transcription (JAK/STAT) signaling pathway in response to inflammatory cytokines. Therefore STAT1 associated with several inflammatory diseases [16-18]. To 
the best of our knowledge there is not enough data about the molecular mechanism of STAT1 in periodontal disease, Of course, recent study shows that Polymorphism of STAT1 (rs3771300) is associated with the severity and clinical factors of periodontal disease and it was shown that the $G$ allele of STAT1 increases the risk of aggressive periodontitis [3]. In addition, STAT1 gene expression was up-regulate by $\mathrm{TNF}-\alpha$, which is involved in the TLR signaling pathway [19]. Recently, one study indicated that stimulation of TLR by ligands led to STAT1 rapid phosphorylation, suggesting that STAT1 plays a major role in TLR-induced inflammation [20]. However, a recent study showed that inhibition of the JAK2/STAT1 signaling pathway did not lead to a decrease induction of TLR 2 mRNA by TNF- $\alpha$ [8]. Therefore, regarding to the absence of enough relevant studies and inconsistency in the results, the aim of this study was to evaluate the correlation between gingival expression of STAT1 and periodontal disease (chronic periodontitis).

\section{Materials and Methods}

\section{Samples}

In this case-control study, 45 subjects were participated. 20 individuals for clinically healthy group and 25 patients with chronic periodontitis for case group.

At first visit, all the local irritating factors including calculus, bacterial plaque, caries, and unfavorable temporary crowns with subgingival margins were removed and the patients were instructed to brush their teeth three times a day and to floss once daily and surgery was scheduled for at least one week later. For chronic periodontitis group, phase I periodontal therapy consisted of supra and subgingival scaling, root planning and polishing and oral hygiene instruction was accomplished at least one month before surgery and periodontal charting and BOP evaluation was performed one week before surgery in order to confirm BOP positivity of the site. Table 1 summarizes the characteristics of the study subjects and sampling sites.

Inclusion Criteria: All the patients were Iranian and were older than 12 recruited from periodontics department of dental faculty of Shahid Beheshti University of medical science. The study protocol was explained to each subject, and written informed consent was obtained prior to enrollment in the study.

Exclusion Criteria: Presence of any known systemic disease, pregnancy and breast feeding, any history of cigarette smoking, alcohol consuming or drug abuse, any history of medication uptake that could affect periodontal conditions such as calcium channel blockers, anticonvulsive and immunosuppressive agents, any history of allergy, orthodontic therapy, or antibiotic therapy in the preceding 6 months. In addition, sampling was not performed around wisdom teeth, teeth with heavy occlusal interferences, teeth with combined perio-endo problems or pericoronitis and pathologies such as ulcers, cysts, abscesses or tumors.

\section{Gingival Tissue Collection}

During the surgical procedures, gingival tissue sample were collected from 20 individuals with clinically healthy gingiva and 25 patients with moderate to severe chronic periodontitis. Gingival biopsy (containing epithelium and connective tissue) were immediately immersed into cryotubes containing RNA Later solution and stored at $-20^{\circ} \mathrm{C}$ until extraction of total RNA.

\section{RNA Extraction and cDNA synthesis}

After homogenizing the gingival tissue, RNA was extracted by RNA isolation kit (in the presence of Lysis/Binding buffer, DNase, washing buffer I, II, and Ellution buffer) according to the manufacturer's protocol (High pure RNA Isolation kit, LOT:12033674001, ROCHE, Germany). The quality of the total RNA was confirmed by the $\% 2$ agarose gel electrophoresis, followed by visualization of the bands using UV Trans illuminator and Gel Doc and observation 3 bands, 5S, 18S, and 28 SrRNA. Its concentration and purity were evaluated by measuring the absorbance at $260 \mathrm{~nm}$ and the $260 / 280 \mathrm{~nm}$ ratio, respectively, using spectrophotometer, and the OD ratio was $>1.8$.

Complementary DNA was synthesized, by reverse transcription .01-5 $\mu \mathrm{g}$ of total RNA in the presence of Reaction buffer, Oligo (dT), Revert Aid ${ }^{\text {TM }}$ M-MuLV Reverse Transcriptase, $\mathrm{MgCl}_{2}$, dNTPs, RiboLock ${ }^{\mathrm{TM}}$ RNase Inhibitor, according to the manufacturer's protocol (Thermo Scientific Reverted First Strand cDNA Synthesis Kit, LOT 00146314, Fermentas, Lithuania).

\section{Quantitative Real-Time PCR}

Gene sequence of STAT1 on chromosome and RNAP2 as housekeeping gene was obtained from NCBI website and designing of forward and reverse primers was performed using Beacon designer Software.

To determine the ideal concentration of primers, different concentrations $(0.5,0.8,1$ and $1.5 \mu \mathrm{M})$ were tested and $0.5 \mathrm{mM}$ for each primer was selected as the best. The primer sequences, product region, predicted amplicon sizes, and Tm are listed at Table 2.

Table 1. Demographic and Clinical Characteristics of Groups.

\begin{tabular}{|c|c|c|}
\hline Variables & Healthy group & Chronic periodontitis group \\
\hline Number of samples & 20 & 25 \\
\hline Age (in years) & $34.50 \pm 11.857$ & $47.48 \pm 9.760$ \\
\hline Sex (male/female) & $8 / 12$ & $8 / 17$ \\
\hline CAL (mm; mean \pm SD) & $2.894 \pm .927042$ & $4.600 \pm .926502$ \\
\hline PD (mm; mean \pm SD) & $2.572 \pm .667839$ & $4.167 \pm 1.131827$ \\
\hline BOP (positive/negative) & $2 / 18$ & $23 / 2$ \\
\hline
\end{tabular}

SD: Standard Deviation 
SYBR Green I real time PCR assay was carried out in final reaction volume of $25 \mu \mathrm{l}$ with $12.5 \mu \mathrm{l}$ of SYBR Green I Master mix $\left(\mathrm{SYBR}^{\circledR}\right.$ Premix Ex Taq ${ }^{\mathrm{TM}}$ II, cat no: RR820L), $1 \mu \mathrm{m}$ of forward and reverse primers, $1.5 \mu \mathrm{m}$ cDNA and $10 \mu \mathrm{m}$ depsi water. Thermal cycling was performed using Rotor gene 6000 machine (QIAGEN, Germany) under the following cycling condition: HOLD at $95^{\circ} \mathrm{C}$ for 1 minute, followed by shuttle heating at $95^{\circ} \mathrm{C}$ for 6 seconds, $54^{\circ} \mathrm{C}$ for 25 seconds and $72^{\circ} \mathrm{C}$ for 30 seconds in $40 \mathrm{cy}-$ cles.

Calculations to determine the relative level of gene expression were made by reference to the RPOL2 in each sample, using cycle threshold method. The data were analyzed by the system software 11. Ct value of reference gene (RPOL2) was subtracted from $\mathrm{Ct}$ value of the target gene (IL-22) to obtain $\Delta \mathrm{Ct}$. After that $\Delta \Delta \mathrm{Ct}$ was calculated ( $\Delta \mathrm{Ct}$ target $-\Delta \mathrm{Ct}$ reference). The calculated $\Delta \Delta \mathrm{Ct}$ was converted to ratio using the ratio formula (ratio $=2-\Delta \Delta \mathrm{Ct}$ ).

\section{Statistical Analysis}

All data were analyzed using SPSS 20.0 statistic software program (IBM Corporation, NY, USA). P value of $\leq 0.05$ was considered statistically significant.

\section{Results}

In Figure 1, PCR products which were electrophoresed on a 1.5\% agarose gel and Specific bands could be observed in each group.

Kolmogorov-Smirnov test showed normality of the distribution of data.

Then, $\mathrm{t}$ test was used for comparing the STAT1 gene expression between healthy and chronic periodontitis groups.

Production of STAT1 mRNA was detected in all gingival tissue samples. The mean relative mRNA level of STAT1 was signifi- cantly higher in the chronic periodontitis group $(1.423 \pm .558817)$ in comparison to control group $(1.00 ; \mathrm{P}<0.01)$. In Figure 2, two groups are compared regarding the STAT1 gene expression.

By using Pearson's correlation coefficient test, there is not any significant correlation between expression of STAT1 and PD or CAL in chronic periodontitis group.

\section{Discussion}

Signal transducers and activators of transcription (STAT) are a family of nuclear proteins mediating the action of a number of cytokines. Among them, STAT1 plays a critical role in the signal transduction pathway of interferon-gamma (IFN-gamma) and growth hormone. STAT1 cascade is one major signaling pathway converting the IFN-gamma signal into gene expression, such as inducible nitric oxide synthase (iNOS), COX, vascular cell adhesion molecules (VCAM) and intercellular cell adhesion molecules (ICAM), critically involved in different pathologies correlated to the inflammatory process [21]. Regarding the presence of the inflammatory mediators and higher expression of adhesion molecules in periodontitis lesions [22-24], this is likely that STAT1 can have a major role in chronic periodontitis.

We found higher expression of STAT1 in chronic periodontitis but can not find any significant correlation between STAT1 expression and PD or CAL, so it does not mean that higher expression of STAT1 leads to further tissue destruction and it probably depends on the predominance of IL-1 cytokine family or IFNs which in turn is a result of TLRs activation.

Saraiva et al., observed that the presence of the G allele for STAT1 was associated with twice as high of a chance to develop aggressive periodontitis, and the most severe form of the disease [3].

Kajita et al. found that the IFNA mRNA and STAT1 gene expression was higher in patients with chronic periodontitis $(\mathrm{P}=0.033)$,

Table 2. Primer Information: Primer sequences, product region, predicted amplicon sizes, and Tm.

\begin{tabular}{|c|c|c|c|c|c|}
\hline Gene & Accession Number & Sequence (5'->3') & Length & Tm & Amplicon Size \\
\hline STAT1 & NM-007315/3 & $\begin{array}{c}\text { GACAGTATGATGAACACA- } \\
\text { GTA }\end{array}$ & 21 & 52.76 & \\
\hline & & TGAAGGAACAGAGTAGCA & 18 & 52.21 & 102 \\
\hline RNAP2 & NM-000937/4 & GACTGTCATTAACAACTG & 18 & 50.63 & \\
\hline & & GTCTTAGAATCAGCAATG & 18 & 50.81 & 75 \\
\hline
\end{tabular}

Figure 1. Electrophoresis of PCR products on the 1.5\% agarose gel- Specific bands for STAT1 and RP2 is clearly observed in each group

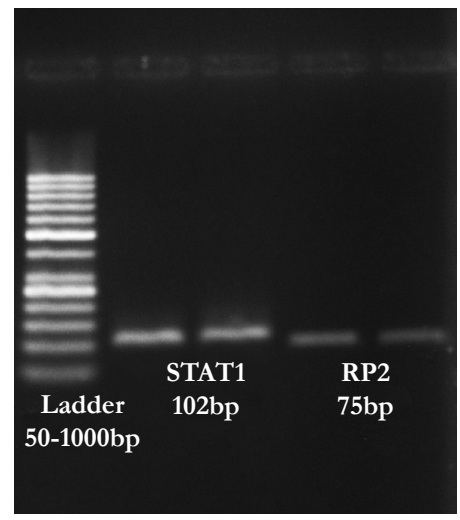


Figure 2. The levels of STAT1 mRNA were significantly upregulated in chronic periodontitis group.

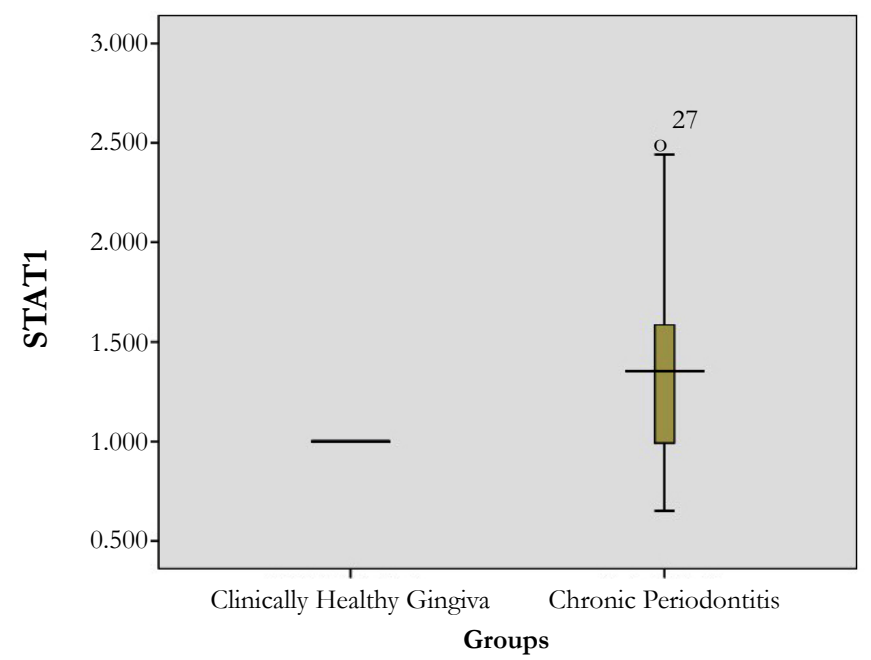

and they reported that PD was associated with increased expression of STAT1 [25].

\section{Conclusion}

There is some similarity between the results, because we also found increased expression of STAT1 in chronic periodontitis and it is well established that IFNs cause increase in STAT1 expression.

In addition, previous reports have demonstrated that both TLRsignaling and IFN $\alpha \beta R$-signaling lead to the phosphorylation of STAT1 $[19,26]$, which leads to increase in expression of STAT1 in response to periodontopathic bacteria.

On the contrary of the Kajita et al. study, we did not find any significant correlation between PD and STAT1 expression and it may be due to different phases of chronic periodontitis which were studied in these two studies. We did not consider early periodontitis.

In addition, it was suggested that some of periodontopathic bacteria activates murine macrophages by HO-1 induction and inhibition of NF-kB and STAT1 pathways [27].

Therefore the difference in the results of different studied can also be attributed to the difference in periodontal plaques and different stages of periodontal diseases.

Gordon et al. found that STAT1 expression in rheumatoid arthritis might have protective not destructive role [28].

Rheumatoid arthritis (RA) is a systemic autoimmune disease characterized by chronic inflammation and joint tissue destruction leading to functional disability.

Periodontitis represents a chronic inflammatory disease affecting tooth supporting tissue and is initiated by oral anaerobic bacteria. Similarities in the clinical and pathological features have been suggested between periodontitis and RA [29-31].

Since, we could not find any correlation between STAT1 expression and PD or CAL, it may be possible that due to some similarities in pathologic features between RA and cronic periodontitis, like RA, expression of STAT1 in chronic periodontitis may have some protective role against tissue destruction.

It is concluded that in chronic periodontitis, inflammatory cytokines such as; IL-1, IL-6 and IL-18 induce the gene expression of STAT1, which probably has some role in regulation of inflammation. With regulation of inflammation, binding the byproducts of periodontopathic of bacteria to TLRs, probably leads to activation of TRAF pathway instead of MyD88, the former causes the synthesis of IFNs and the latter causes the synthesis of IL-1 family of inflammatory cytokines. Of course in order to prove the above hypothesis, more studies are needed.

\section{Acknowledgement}

The authors wish to acknowledge all the patients for their cooperation in this study.

This study was granted by Iran Center for Dental Research, Dental School, Shahid Beheshti University of Medical Sciences. The authors report no conflicts of interest related to present study.

\section{References}

[1]. Berezow AB, Darveau RP (2011) Microbial shift and periodontitis. Periodontol 55(1): 36-47.

[2]. Amini Behbahani A, Sattari M, Mofid R, Ganji A (2014) Interleukin-22 (IL-22) Gingival Gene Expression and GCF Concentration in Periodontal Health and Disease. Int J Dentistry Oral Sci 1(2): 1-4.

[3]. Saraiva AM, de Fátima Correia Silva J, Alves e Silva MR, da Costa JE, Gollob KJ, et al., (2013) Transcription factor STAT1 gene polymorphism is associated with the development of severe forms of periodontal disease. Inflamm Res 62(6): 551-554.

[4]. Cochran DL (2008) Inflammation and bone loss in periodontal disease. J Periodontol 79(8 Suppl): 1569-1576.

[5]. Lima PM, Souza PE, Costa JE, Gomez RS, Gollob KJ, et al. (2010) Agressive and chronic periodontitis correlate with distinct cellular sources of key immunoregulatory cytokines. J Periodontol 82(1): 86-95.

[6]. Gomez RS, Dutra WO, Moreira PR (2009) Epigenetics and periodontal disease: future perspectives. Inflamm Res 58(10): 625-629.

[7]. Dutra WO, Moreira PR, Souza PE, Gollob KJ, Gomez RS (2009) Implications of cytokine gene polymorphisms on the orchestration of the immune response: lessons learned from oral diseases. Cytokine Growth Factor Rev 20(3): 223-232.

[8]. Di Benedetto A, Gigante I, Colucci S, Grano M (2013) Periodontal disease: linking the primary inflammation to bone loss. Clin Dev Immunol 2013: $1-7$.

[9]. Madianos PN, Bobetsis YA, Kinane DF (2005) Generation of inflammatory stimuli: how bacteria set up inflammatory responses in the gingiva. J Clin 
Periodontol 32(Suppl 6): 57-71.

[10]. Slots J, Genco RJ (1984) Black-pigmented Bacteroides species, Capnocytophaga species, and Actinobacillus actinomycetemcomitans in human periodontal disease: virulence factors in colonization, survival, and tissue destruction. J Dent Res 63(3): 412-421.

[11]. Tabeta K, Shimada Y, Tai H, Ishihara Y, Noguchi T, et al. (2009) Assessment of chromosome 19 for genetic association in severe chronic periodontitis. J Periodontol 80(4): 663-671.

[12]. Yucel-Lindberg T, Bage T (2013) Inflammatory mediators in the pathogenesis of periodontitis. Expert Rev Mol Med 15: e7.

[13]. Graves DT, Cochran D (2003) The contribution of interleukin-1 and tumor necrosis factor to periodontal tissue destruction. J Periodontol 74(3): 391-401.

[14]. Page RC (1991) The role of inflammatory mediators in the pathogenesis of periodontal disease. J Periodontal Res 26(3 Pt 2): 230-242.

[15]. Kim HS, Lee MS (2007) STAT1 as a key modulator of cell death. Cell Signal 19(3): 454-465.

[16]. Pinto LA, Steudemann L, Depner M, Klopp N, Illing T, et al. (2007) STAT1 gene variations. IgE regulation and atopy. Allergy 62(12): 1456-1461.

[17]. Harrison DA (2012) The Jak/STAT pathway. Cold Spring Harbor perspectives in biology 4(3): a011205.

[18]. Kisseleva T, Bhattacharya S, Braunstein J, Schindler CW (2002) Signaling through the JAK/STAT pathway, recent advances and future challenges. Gene 285(1-2): 1-24.

[19]. Rhee SH, Jones BW, Toshchakov V, Vogel SN, Fenton MJ (2003) Toll-like receptors 2 and 4 activate STAT 1 serine phosphorylation by distinct mechanisms in macrophages. J Biol Chem 278(25): 22506-22512.

[20]. Luu K, Greenhill CJ, Majoros A, Decker T, Jenkins BJ, et al. (2014) STAT1 plays a role in TLR signal transduction and inflammatory responses. Immunol Cell Biol 92(9): 761-769.

[21]. de Prati AC, Ciampa AR, Cavalieri E, Zaffini R, Darra E, et al. (2005) STAT 1 as a new molecular target of anti-inflammatory treatment. Curr Med Chem 12(16): 1819-1828.
[22]. Dosseva-Panova VT, Popova CL, Panov VE (2014) Subgingival microbial profile and production of proinflammatory cytokines in chronic periodontitis. Folia Med (Plovdiv) 56(3): 152-160.

[23]. Bansal T, Pandey A, Deepa D, Asthana AK (2014) C-Reactive Protein (CRP) and its Association with Periodontal Disease: A Brief Review. J Clin Diagn Res 8(7): ZE21-24.

[24]. Mohangi GU, Singh-Rambirich S, Volchansky A (2013) Periodontal disease: Mechanisms of infection and inflammation and possible impact on miscellaneous systemic diseases and conditions. SADJ 68(10): 462, 464-467.

[25]. Kajita K, Honda T, Amanuma R, Domon H, Okui T, et al. (2007) Quantitative messenger RNA expression of toll-like receptors and interferon-alpha1 in gingivitis and periodontitis. Oral Microbiol Immunol 22(6): 398-402.

[26]. Toshchakov V, Jones BW, Perera PY, Thomas K, Cody MJ, et al. (2002) TLR4, but not TLR2, mediates IFN- $\beta$-induced STAT1 $\alpha / \beta$-dependent gene expression in macrophages. Nat Immunol 3(4): 392-398.

[27]. Choi EY, Choe SH, Hyeon JY, Choi JI, Choi IS, et al. (2015) Carbon monoxide-releasing molecule-3 suppresses Prevotella intermedia lipopolysaccharide-induced production of nitric oxide and interleukin- $1 \beta$ in murine macrophages. Eur J Pharmacol 764: 22-29.

[28]. Gordon RA, Grigoriev G, Lee A, Kalliolias GD, Ivashkiv LB (2012) The interferon signature and STAT1 expression in rheumatoid arthritis synovial fluid macrophages are induced by tumor necrosis factor $\alpha$ and counterregulated by the synovial fluid microenvironment. Arthritis Rheum 64(10): 3119-3128.

[29]. Mercado FB, Marshall RI, Klestov AC, Bartold PM (2001) Relationship between rheumatoid arthritis and periodontitis. J Periodontol 72(6): 779-787.

[30]. Mercado FB, Marshall RI, Bartold PM (2003) Inter-relationship between rheumatoid arthritis and periodontal disease. A review. J Clin Periodontol 30(9): 761-772.

[31]. Bartold PM, Marshall RI, Haynes DR (2005) Periodontitis and rheumatoid arthritis: a review. J Periodontol 76(11Suppl): 2066-2074. 